
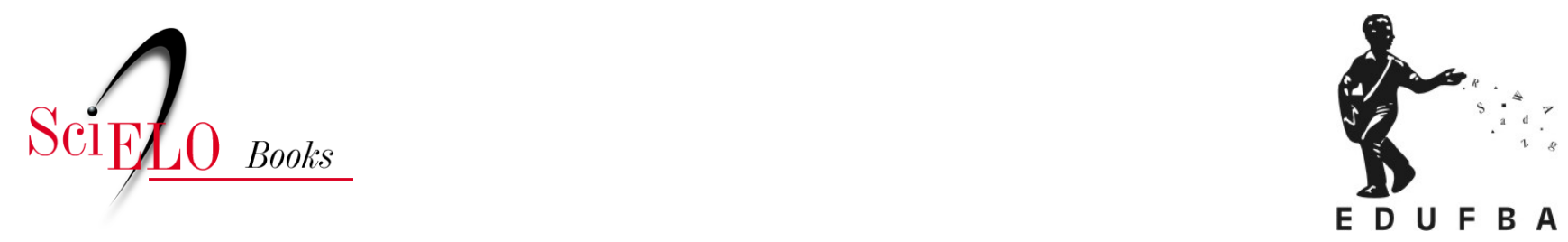

\title{
Capítulo 3 - De mercado à vila práticas alimentares e higiene frente ao processo de gentrificação na cidade de Salvador, Bahia
}

\author{
Diego Marinho Calabrese \\ Ligia Amparo-Santos
}

\section{SciELO Books / SciELO Livros / SciELO Libros}

CALABRESE, D.M., and AMPARO-SANTOS, L. De mercado à vila: práticas alimentares e higiene frente ao processo de gentrificação na cidade de Salvador, Bahia. In: BOSI, M.L.M., PRADO, S.D., And AMPARO-SANTOS, A., comps. Cidade, corpo e alimentação: aproximações interdisciplinares [online]. Salvador: EDUFBA, 2019, pp. 99-118. ISBN: 978-65-5630-010-8.

https://doi.org/10.7476/9786556300108.0006.

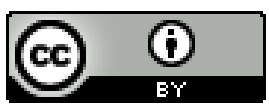

All the contents of this work, except where otherwise noted, is licensed under a Creative Commons Attribution 4.0 International license.

Todo o conteúdo deste trabalho, exceto quando houver ressalva, é publicado sob a licença Creative Commons Atribição 4.0. 


\section{De mercado à vila práticas alimentares e higiene frente ao processo de gentrificação na cidade de Salvador, Bahia ${ }^{1}$}

\section{INTRODUÇÃO}

Este ensaio entrecruza três temáticas distintas - gentrificação, higiene e práticas alimentares -, ao passo que se revelam complementares quando tomado como ponto de interlocução o percurso de sucessivas modificações urbanas, de infraestrutura e sociais na atual Vila Caramuru, antes

1 Estudo parte do projeto intitulado "Corporalidades, comensalidades e alimentação saudável na Bahia: um estudo sobre as práticas corporais e alimentares em camadas populares sob a ótica da promoção da alimentação saudável". Tal projeto contou com o apoio financeiro da Fundação de Amparo à Pesquisa do Estado da Bahia (Fapesb) e bolsa financiada pela Coordenação de Aperfeiçoamento de Pessoal de Nível Superior (Capes). 
Mercado do Rio Vermelho e Mercado do Peixe - nome pelo qual o espaço é mais conhecido - em Salvador, Bahia.

Os argumentos contidos neste texto emergem de inquietações surgidas em torno da necessidade de aprofundamento sobre o fenômeno da gentrificação nos espaços públicos de comensalidade dentro das cidades, no qual as feiras e os mercados populares revelam-se como importantes neste contexto, ainda que em um cenário de sucessivas intervenções urbanas que visam, por seu turno, supostamente "embelezamento", "modernização" e higienização dos mesmos.

"De mercado à vila" é parte de um estudo maior o qual objetiva compreender as práticas alimentares e de higiene perante o processo de gentrificação em curso em um espaço de comensalidade na cidade de Salvador. ${ }^{2}$

Não se trata, portanto, de um tratado teórico sobre a temática e tampouco possui a intenção de oferecer uma análise histórica sobre o fenômeno da gentrificação no locus pesquisado.

Trata-se de um estudo de cunho qualitativo e analítico, que tomou como substrato os discursos midiáticos de recortes dos principais jornais de circulação impressa em Salvador, propondo uma interlocução com escritos oriundos, particularmente, da socioantropologia da alimentação e nutrição e antropologia urbana.

A discussão se estrutura em torno do conceito de gentrificação ou gentrification (do inglês), termo cunhado em 1964 pela socióloga britânica Ruth Glass, ao se referir às alterações por ela observadas na estrutura social e mercados imobiliários em certas áreas do centro de Londres. Glass (1964, p. 17) observou:

Um por um, muitos dos bairros da classe trabalhadora foram invadidos pela classe média - alta e baixa ... Uma vez que esse processo de gentrificação inicia em um distrito, ele continua rapidamente até que todos ou a maioria dos ocupantes da classe trabalhadora sejam deslocados e todo o caráter social do distrito é alterado. ${ }^{3}$

2 Dissertação de mestrado em andamento.

3 "One by one, many of the working class quarters have been invaded by the middle class - 
Van Weesep (1994) marca a ideia de que o processo de gentrificação está profundamente enraizado nas dinâmicas sociais e nas tendências econômicas. Afirma ainda que seus sinais, efeitos e trajetórias são, em grande medida, determinados pelo seu contexto local: as características físicas e sociais dos bairros em questão, as posições e os objetivos dos atores, as funções dominantes da cidade, a natureza da reestruturação econômica e a política do governo local. Finalmente, defende-se que o "porquê" da gentrificação é menos importante que o "como" e as repercussões do processo, algo que corrobora com a visão empregada neste escrito.

Além disso, Lees, Slater e Wyly (2008) afirmam que a gentrificação tornou-se uma "valiosa lente" através da qual se dá para examinar uma variedade de fenômenos que se cruzam em um contexto de cidade e/ou vizinhança. Insere ainda no debate a ideia de "geografia do consumo" e exclusão social diante da lógica embutida no processo de gentrificação, o qual acrescentamos o empenho que gira em torno da higienização dos espaços.

Com a higiene, introduz-se um novo padrão de comportamento, montando novos mecanismos de condicionamento social, exigindo um novo pensamento, novos cálculos e, como bem afirma Brás (2008), tornou-se símbolo de sociedade bem-educada e simultaneamente de "pessoa de bem". Pontua-se, portanto, que tal ensaio se ocupará de trazer elementos de um "urbanismo higienista", ou seja, de um higienismo social, que aos olhos de Ferreira Filho (1998), há um viés ideológico nessas ações, no qual, ao final do século XIX e primeiras décadas do século $X X$, inscreve-se num projeto de modernização, de "desafricanização das ruas", guardando, de certa maneira, semelhanças com movimentos de gentrificação atuais, ao menos no Brasil.

Mercados e demais espaços de comensalidade revelam-se alvos privilegiados de tais iniciativas que partem do poder público, bem como

upper and lower ... Once this process ' $f$ 'gentrificat'on' starts in a district it goes on rapidly until all or most of the working class occupiers are displaced and the whole social character of the district is changed". 
do setor privado movidos por uma lógica neoliberal. Sob adjetivos eufemistas que maximizam características positivas do processo, percebe-se uma reflexão crítica insuficiente sobre o processo de gentrificação nesses espaços, seus efeitos diante de possíveis mudanças no perfil dos frequentadores e, consequentemente, nas práticas alimentares.

Em seu Guia de ruas e mistérios, Jorge Amado nos leva a viajar pelas ruas da cidade da Bahia e traz consigo uma definição poética que nos faz refletir sobre espaços comensais populares - em particular, o Mercado do Peixe - e o que abordamos como práticas alimentares populares:

Esses são os mercados populares. [...] dão direito à conversa solta e sem pressa, ao trago da cachaça, ao caldo da lambreta, ao vatapá oloroso, ao sarapatel de miúdos de porco. Não é possível comparar os frios mercados da sociedade de consumo com esses cálidos centros de vida popular. (AMADO, 1991, p. 398)

As práticas ligadas à comensalidade popular se expressam não apenas pelo que se é consumido, neste caso, as comidas do cotidiano ou encaradas como "pesadas", mas também pelos modos de interação e sociabilidade dos sujeitos, maneiras à mesa, até mesmo a apresentação das refeições, sob o ponto de vista estético. Desta maneira, entende-se aqui que o processo de gentrificação e consequente higienização em tais espaços refletem diretamente nas práticas alimentares de seus frequentadores, dadas sucessivas tentativas de formalização das relações interpessoais, do câmbio do perfil da clientela e até mesmo da comercialização de versões mais "gourmetizadas" e caras de pratos tradicionais, oferecidas ao consumidor como uma forma simbólica de marcar diferenças sociais.

Diante da tamanha complexidade e da dinâmica construção do fenômeno, este ensaio se estruturará a partir da consideração dos elementos que se imbricam em torno da problemática. Desejando seu melhor entendimento, pretende-se trazer uma abordagem a partir dos diferentes momentos do Mercado, destacando seus eventos históricos, suas relações com o processo de gentrificação e higienização, e, finalmente, serão abordadas possíveis modificações no campo das práticas alimentares. 


\section{DE MERCADO À VILA}

Ideias urbanísticas de modernização e higienização, como as do barão Haussman, em Paris, que circularam por todo o mundo, sobretudo seus feitos mais autoritários, tiveram suas reproduções brasileiras, apesar do contexto urbano bastante distinto. Em Elogios aos errantes, Jacques (2012) nos leva a uma viagem ao longo do tempo, trazendo diferentes perspectivas de alguns personagens reais que escreveram sobre o período de rápida metamorfose urbana na cidade do Rio de Janeiro no início do século XX. É nesse período que Olavo Bilac, por exemplo, exaltava, apoiava e enaltecia os feitos da reforma do prefeito - viva "as picaretas regeneradoras!”. Já Lima Barreto, diferentemente, era avesso a tudo o que se referia à modernização: a nova avenida, disse ele, é como uma "mulata apertada em vestido francês". Por sua vez, João do Rio se colocava em um difícil meio-termo: ao mesmo tempo em que criticava a radicalidade e o autoritarismo do momento, sabia que também faziam parte desse processo modernizador, que se mostrava inevitável. A autora então afirma que a ambiguidade era inerente a uma crítica moderna da própria modernidade, ao dialogar com a perspectiva "errante" de João do Rio.

Semelhanças ocorrem na cidade de Salvador, com a figura do prefeito J. J. Seabra (1912-1916), que, como bem nos lembra Santos (2008), há um clássico exemplo da destruição da tradicional Igreja da Sé, palco dos famosos discursos do padre Antônio Vieira durante o século XVI, para possibilitar a circulação dos bondes no centro da cidade. Tal fato gerou inúmeras polêmicas, debates e repúdios nos meios intelectuais e jornalísticos.

Todavia, é importante destacar que foi nas décadas de 1950 e 1960 que se assentaram as bases para o desenvolvimento técnico e econômico do estado da Bahia que, como apontado por Santos (2008), houve a existência de um processo de modernização mais intenso e próximo de uma lógica urbano-industrial em curso na cidade, que, nas décadas de 1980 e 1990, se acentua drasticamente tomando, possivelmente, novos contornos com a economia da cidade voltada ao setor de serviços. Salvador, 
segundo Risério (2004), passa a ser uma cidade centrada na "economia do lazer”, pautada nos elementos turísticos, do lúdico e do simbólico.

Contudo, essas iniciativas modernizantes pouco alteraram a configuração e a dinâmica da cidade. A metrópole Salvador, ainda que como espaço periférico, integra os movimentos da era globalizada, entretanto, incorpora-os ao modo próprio como equaciona sua herança histórica e a atualiza.

Assim, o Mercado do Peixe, marcado pela linha tênue entre manutenção da tradição e abertura à modernidade, revela-se como rico espaço para se discutir a atualidade dos projetos de assepsia, limpeza social, vigilância, privatização e controle urbano, em um contexto de comensalidade e sociabilidade popular. Tal processo se dá em meio a uma eterna luta que a urbe ainda trava contra o estigma de "cidade suja", criado pelas escritas dos viajantes que aqui chegavam há mais de dois séculos atrás. (ARAUJO, 2006)

Em uma conjuntura citadina, cabe salientar a relevância dos bairros como espaços de atuação. Como bem aponta Certeau (1994), o bairro é uma categoria importante para se pensar a configuração das relações dos habitantes da cidade com o espaço. Diante disso, de início mostra-se importante trazer algumas questões que marcam o bairro do Rio Vermelho, onde está localizado o espaço do Mercado, questões essas que nos permitem compreender as dinâmicas que giram em torno da ideia de tradição e modernidade, envoltas no processo particular de gentrificação do espaço.

De maneira breve, o mito de origem do Rio Vermelho se funda no naufrágio de Diogo Alvares, o Caramuru, no século XVI. Bem acolhido pelos índios tupinambás que por lá viviam, Caramuru logo passou a ser estimado na região, onde conheceu a índia Catarina Paraguaçu, com quem se casou. Já no século XVII, logo após a Invasão Holandesa em 1624, moradores se instalam no local. Aos poucos, o bairro, predominantemente formado por pescadores, passou a servir de veraneio para as famílias ricas da cidade.

Atualmente, o bairro circula entre os principais destinos boêmios de Salvador. Estão ali alguns dos largos e baianas de acarajé mais famosos 
da cidade, além de cafés, restaurantes, diversos bares e o Mercado do Peixe. Além disso, o lugar é bastante disputado pelo mercado imobiliário e também é tido como um recanto de artistas, intelectuais, estudantes universitários ou, como denomina Lees, Slater e Wyly (2008), de "classe criativa". 4

As ruas do Rio Vermelho também abrigam uma das maiores festas populares de Salvador: a Festa de Iemanjá. ${ }^{5} \mathrm{O}$ antigo Mercado do Peixe, antes de ser transformado em Vila Caramuru, participava desses festejos, era enfeitado com as cores que remetem a Iemanjá, azul e branco, e atraía uma diversidade de público. Tal contexto se modifica com o atual instalado e guarda semelhanças com modelos de festas particulares já inseridas no cenário "camarotizado"” da cidade, tal como ocorre na

4 No Rio Vermelho, moraram artistas ilustres do cenário local e nacional, como: Carlos Bastos, Carybé, Jenner Augusto e Mario Cravo - além do casal de escritores Jorge Amado e Zélia Gattai, cuja casa hoje é um museu, a Casa do Rio Vermelho -, que transitaram lado a lado com os moradores da arte musical, como o pianista Carlos Lacerda, a musicista Walkyria Knittel, ou ainda das artes cênicas, como João Miguel. Talvez impulsionados por esses antigos moradores que, aos poucos, inúmeras galerias e ateliers de artes plásticas surgiram e definiram o bairro como referência em artes. (CALABRESE, 2013, p. 36)

5 Segundo Manoel Quirino (1946), a notícia mais antiga em relação aos festejos dedicados à Rainha das Águas foi a descrição da festa, pelo referido autor, no século XIX, quando os organizadores da festa ainda eram escravos africanos e o evento ocorria em outro espaço. O formato mais próximo ao atual apresenta-se desde o ano de 1923, como a maior manifestação pública do candomblé em Salvador, criada por pescadores para reverenciar a Mãe D’Água, em forma de apelo, num momento de baixa na pesca. Assim, todos os anos, no dia 2 de fevereiro, enchem-se balaios de flores e de presentes para a Rainha do Mar, e festejos que são acompanhados por barracas em toda a extensão da orla, com desfiles de blocos, apresentações de batuques, afoxés e sambas de roda, fazendo da localidade um celeiro de criatividade, aliando-se a isso diversos tipos de apresentações e manifestações, inclusive as político-partidárias. Agregam-se ainda eventos paralelos, tais como as famosas feijoadas. (SILVA, 2006, p. 113)

6 Entende-se por “camarotização" o processo iniciado na década 1980, em Salvador, com a introdução de "dinâmicas típicas do mundo dos negócios, dando lugar à configuração do que pode ser chamado de carnaval-negócio, marca registrada que particulariza a forma contemporânea do Carnaval da Bahia”. (MIGUEZ, 2011, p. 287) Insere-se nesse contexto a instalação de gigantes camarotes nos percursos do Carnaval, em que, em um movimento de apropriação do espaço público, são realizadas festas particulares com áreas VIP. Dialogando com o contraste percebido por DaMatta (1997, p. 35), em referência aos Carnavais de rua e aos Carnavais de clube, sendo "um Carnaval que é aberto - no sentido literal e metafórico da expressão - e um Carnaval que é fechado e tem tendências aristocratizantes”, respectivamente. 
Festa do Senhor do Bonfim e Nossa Senhora da Conceição com suas versões "light".

O Mercado do Rio Vermelho - ou melhor, Mercado Municipal do Rio Vermelho -, oficialmente, nasce com formato de feira em um galpão fechado que funcionava durante o dia, conformação diferente da atual, localizado no Largo da Mariquita - do outro lado da rua -, em que eram comercializados peixes, frutos do mar e também havia alguns espaços destinados à comercialização de comidas e bebidas.

Um trecho de reportagem da década de 1970 revela um pouco como era o espaço e como o mesmo era visto por alguns moradores do bairro:

Também [em comparação ao bairro do Rio Vermelho, à época] sem nenhuma estrutura, ou sistema higiênico, funcionam no Largo, uma peixaria e um mercado, que na realidade são verdadeiros atentados à saúde pública. A peixaria exala um odor insuportável, sentido até por quem passa de veículo. O mercado público é um antro de desocupados e alcóolatras. Como bem disse uma senhora residente na área, 'nenhuma mulher que se preza entra neste mercado'. As barracas de comida ali estabelecidas, jogam o lixo na calçada do mercado, ou seja, no próprio largo. [...] para uma criança ou uma senhora atravessar a Mariquita, é preciso ter muita paciência e tempo. Além do mais, inexplicavelmente, o Largo tem o poder de atrair vários malucos. (LARGO..., 1976, p. 6)

A casa e a rua são referidas por DaMatta (1997) sob diferentes concepções em uma ordem decrescente de segurança e organização, respectivamente. No trecho acima, a rua é encarada como espaço da marginalidade, da malandragem, da vagabundagem, da loucura e da falta de higiene.

É possível que a senhora entrevistada, de maneira inconsciente ou não, em um movimento de distanciamento pautado em um discurso moralizado, perceba tal espaço e os sujeitos que o frequentam como

7 "Nas festas da Conceição e do Bonfim, há outras festas em paralelo que se denominam respectivamente Conceição Light e Bonfim Light. Ambas são festas privadas em espaços localizados no entorno, voltadas para um público jovem de classe média e alta, ou seja, festa para 'gente bonita'. Oportuniza que todos 'rendam homenagens' aos santos católicos e aos orixás, mas numa festividade mais light, não precisa se misturar ao povo miscigenado com hábitos e atitudes mais 'pesadas'. Em suma, festa é signo da cultura baiana que hoje se transforma em um produto que percorre a cidade". (SANTOS, 2008, p. 129) 
elementos "sujos", concordando com Douglas (2014), quando marca que a sujeira seria essencialmente a desordem, principalmente para o bairro do Rio Vermelho que, àquela época, era ocupado por casas de veraneio da classe média e alta.

Determinado entendimento corrobora com o que aponta Araujo (2006) sobre a noção de que "classes pobres" e "classes perigosas" - expressão cunhada possivelmente no início do século XIX - eram duas expressões que denotavam e descreviam a mesma "realidade".

Dessa maneira, as classes populares passaram a ser vistas naturalmente como classes perigosas, já que, além de oferecer problemas para a organização do trabalho e da manutenção da ordem pública, ofereciam perigo sob o ponto de vista higiênico.

Na década de 1980, o Mercado do Peixe, então, é transferido para o outro lado da rua, mais próximo ao mar, e, por certo tempo, as características de feira foram mantidas. Contudo, o comércio das comidas e bebidas se expandiu, predominando no espaço, restringindo progressivamente a feira.

O Mercado do Peixe, então, assume definitivamente o aspecto boêmio do bairro do Rio Vermelho, mas ainda mantendo sua característica popular. É marcada a tradição do Mercado, se afirmando como a melhor opção da cidade para a famosa "saideira". ${ }^{8}$ Nesse período, o então Mercado do Peixe, localizado à beira-mar e com diversos bares no mesmo ambiente, se consolida como espaço popular foi mantida ainda que a época seus preços fossem questionados - tendo como símbolo o conhecido "feijão da madrugada", já que o mesmo passou a funcionar 24 horas:

Festa de jornalista, intelectual e artista que se preze costuma terminar no Mercado do Rio Vermelho, com o sol amanhecendo sobre o azul da Paciência. O velho e bom mercado, onde se come buchada, mocotó e xinxim de bofe sem fazer cara feia. Cerveja no copo de geleia, comida na travessa de barro, mesa de madeira sem toalha. Tudo muito à vontade. Se falta luxo, os preços se aproximam bastante dos cobrados nos grandes

8 Última dose de bebida alcoólica que se toma em uma festa ou bar antes da volta para casa. 
restaurantes. Uma moqueca de camarão, por exemplo, não sai por menos de CR\$ 7 mil e um prato de feijoada, por CR\$2,8 mil. ${ }^{9}$ A vantagem é o funcionamento ininterrupto 24 horas por dia. São 34 boxes para a venda de comida, bebida, artesanato e peixe. Apenas meia dúzia dos boxes são peixarias, que só funcionam pela manhã. (TUDO..., 1994, p. 4)

Ali, onde se come "sem fazer cara feia”, marcando, em certa medida, a “ojeriza” ao popular que envolve, diga-se de passagem, todos os sentidos: a estética da comida popular - a cerveja no copo de geleia, a comida servida na travessa de barro, a mesa sem toalha - seus cheiros, os sabores, os temperos, aspectos que vão além da preparação e que compõem um verdadeiro mosaico icônico de representações do comer popular. O "velho e bom mercado", ambiente de informalidade, em permanente ausência de serviços públicos básicos, passa a ser, naquele momento, enquadrado em uma fase denominada como de "decadência".

Tal cenário de abandono já se encontrava instalado, inclusive despertando o desejo de alguns comerciantes de que o espaço passasse para o domínio privado, em contraponto à ausência do poder público. Tal como pode ser observado nesta matéria jornalística em tom de denúncia sobre tal estado:

O antigo mercado de peixe do Rio Vermelho, está abandonado pela prefeitura e já apresenta sinais de decadência, além de deficiências na rede de esgoto sanitário. Apesar de vender pescado e outros alimentos, a higiene inexiste e os quatro sanitários públicos (femininos e masculinos) estão com vazamentos, transformando-se num foco de mau cheiro. Os comerciantes queixam-se das taxas que pagam, culpam a prefeitura pelo estado crítico e querem que o mercado seja privatizado. O processo de degradação do mercado começou há muito tempo. Os quatro sanitários públicos construídos na área externa não foram reformados, a maioria das portas não fecha, oferecendo cenas degradantes. As águas fétidas dos sanitários escorrem para o calçadão. $\mathrm{O}$ amplo calçamento de pedras portuguesas está totalmente esburacado e cheio de água estagnada. A rede de águas

9 Na data da reportagem, o salário mínimo possuía o valor de CR\$ 42.829,00. Disponível em: http://www.oabsp.org.br/subs/saoluizdoparaitinga/noticias/valores-do-salario-minimo-nacional-desde-sua. 
pluviais está entupida, represando as águas de lavagem de vísceras de peixes e outros alimentos. $\mathrm{O}$ que era para ser um local limpo virou área de risco para os feirantes e consumidores. (MENDONÇA, 2000, p. 4)

Alguns investimentos pontuais são realizados a fim de manter o seu posto de "maior reduto da boemia baiana" (SANTOS, 2003), ainda marcado por sua frequência variada, trilha sonora também eclética e a presença de pratos populares da culinária baiana, como o sarapatel e o arrumadinho.

O resultado de tal processo é uma dinâmica "gangorra" de investimento e desinvestimento ao longo do tempo e no espaço, em um processo contínuo de desenvolvimento geográfico desigual. (HARVEY, 1973, 1982, 2003; SMITH, 1982, 1984) Lees (2008) nos chama ainda a atenção ao fato de que o capitalismo está sempre criando novos lugares, novos ambientes projetados para lucro e acumulação, no processo de desvalorização de investimentos e paisagens anteriores.

O ponto é que o processo que culmina em uma “decadência” espacial não é um fenômeno inocente, tampouco surge apenas do desinteresse particular de antigos frequentadores. É importante frisar que tal fenômeno está intimamente ligado a um desinvestimento, que chamo de proposital, em que narrativas de declínio e morte têm sido ultrapassadas por um discurso neoliberal de regeneração e renascença. (DAVIDSON; LEES, 2005)

A globalização espelha e espalha tais iniciativas e traz consigo signos que sustentam o moderno como algo homogeneizado, passível de reprodução e, portanto, pertencente ao mundo, retirando cada traço de identidade local, ou melhor, os ressignificando:

A reforma do Mercado do Peixe, que será reinaugurado sexta-feira, custou cerca de R\$ 3 milhões. [...] A obra é fruto de uma Parceria Público Privada (PPP) feita entre a prefeitura e o Grupo Schincariol, que garantiu, assim, o direito de ser a única marca de cerveja vendida no espaço nos próximos dez anos. [...] O design da estrutura, feito pela Fundação Mário Leal Ferreira, é bem parecido com o dos bares que estão à beira do Lago Paranoá, em Brasília, e no Porto Madero, em Buenos Aires, na Argentina. (BRITO, 2010, p. 12) 
A reforma, que além da pretensão de trazer ares modernos e um caráter global, baseia-se em um discurso de higiene de caráter individualista e liberal. O discurso ideológico, promovido pelo poder público em torno da cidade moderna e civilizada, gira em torno do desejo de transformar a barroca Salvador em uma metrópole global.

De maneira geral, tal conjunto de práticas e experiências é direcionado para camadas populares da população, segundo características sociais e culturais dominantes, além do que um dos desdobramentos dessa linha de pensamento leva ao funcionamento de um código moral que responsabiliza os indivíduos pela adoção e insistência em certos padrões de comportamento, preconizando mudanças desses padrões.

Nesta esteira, o horário de funcionamento do Mercado foi modificado, assim como as práticas de limpeza e o preparo de refeições readaptado e, em um primeiro momento, notou-se uma mudança de público:

O primeiro sábado de funcionamento do Mercado do Rio Vermelho, conhecido popularmente como Mercado do Peixe, foi marcado pelo sol e pela ocupação de várias mesas por clientes antes das 10 horas, numa situação muito diferente do que acontecia antes da revitalização da área, que foi inaugurada no último dia 10. [...] A gerente do Bar e Restaurante Travessia, Eleide São Pedro Teles, que trabalha há 13 anos no Mercado do Peixe, explicou que o movimento da última sexta-feira foi muito bom. A gerente do Beleza Rara, Itamara Nunes, explicou que a mudança do horário de funcionamento, que passou a ser das 8 [da manhã] às 4 horas [da tarde], permite que a limpeza e preparo dos alimentos sejam feitos de forma mais correta. Feliz, José Batista Junior, do Tô em Casa, diz que a frequência de clientes melhorou em quantidade e em qualidade. Ele disse que a reforma atraiu um público mais tranquilo ao contrário do ocorria até o final do ano passado. (MOURA, 2010, p. A10)

O trecho acima apresenta uma série de aspectos tomados como positivos pelos próprios feirantes, à época, incluindo que a "qualidade do público melhorou", o que revela um pensamento que leva em conta uma tendência de classificar os sujeitos sob o ponto de vista moral. Assim, podemos fazer uma analogia do termo "qualidade" e seu cunho classista com o termo "gente bonita", por sua vez, marcado pela identificação com 
valores de 'bom-gosto' e autodisciplina corporal, um habitus coincidente com alguns dos modelos representados para o "branco" jovem de classe média em Salvador (PINHO, 2005), já bastante difundido nas mais diversas conversas cotidianas e envolto numa dimensão racializada.

Essa possível "desordem” apresentada pelos textos jornalísticos costuma centrar-se em uma análise superficial e dual do fenômeno, culminando em um julgamento do que seria um espaço "bem" ou "mal" frequentado. Esse seria um julgamento questionável, ao passo que são baseados em códigos sociais de comportamento elaborados por valores de moralidade, como apontado anteriormente. Tais valores morais, legitimadores do modo de viver politicamente correto, são, por vezes, unifocais, perante uma realidade social multifacetada.

DaMatta (1987) chama de "gramática dos espaços" as implicações que os diversos espaços têm na forma de pensar e de comportar-se das pessoas. Segundo ele, a esses diversos espaços pertencem esferas de significação que delineiam uma visão de mundo e éticas particulares que constituem a própria realidade e ainda, portanto, normalizam e moralizam o comportamento a partir de perspectiva própria. Ou seja, os locais aqui possuem agência no pensar e no comportar dos sujeitos.

Partindo deste pressuposto, poder-se-ia imaginar uma "reestruturação" também do comportamento dos sujeitos. Todavia, um dos principais aspectos modificados relacionados com a reestruturação do espaço - o perfil dos frequentadores - não foi necessariamente substituído, tampouco alguns hábitos de limpeza e organização. Assim, tal reforma não conseguiu dar conta do projeto higienizador do espaço:

Reformado há 2 anos, Mercado do Peixe ainda sofre com sujeira. $\mathrm{O}$ anúncio de uma grande obra com direito a mirante, anfiteatro, reforma dos banheiros e dos boxes, melhorias na pavimentação e estacionamento prometiam salvar o reduto dos boêmios do Mercado do Peixe, no Rio Vermelho. No lugar dos boxes de alvenaria e toldos chegaram as lonas, o calçamento foi requalificado, os banheiros e a infraestrutura local melhoraram. Até aí, tudo bem, mas há um velho problema que não há reforma que resolva: a sujeira. 'É um povo muito mal-educado. As pessoas jogam 
copos de plástico no chão... E ainda tem o lixo jogado pelos ambulantes que passam por aqui', ressalta o diretor da Associação dos Permissionários do Mercado do Peixe, Antônio Nunes. O paulista, Roberto Perez, 56, está em Salvador a trabalho pela sexta vez e resolveu conhecer ontem o famoso Mercado do Peixe. Sofreu uma decepção. Sentar para comer, nem pensar. 'Achei muito feio e desorganizado. Não me parece muito higiênico'. (PEREZ, 2012, p. 22-23)

Santos (2012), no período de sua pesquisa no local, percebeu que o mesmo apresentava uma espécie de "segregação" espacial velada já que possuía dois ambientes distintos, que nomeou como "lado A" e "lado B". Para Mary Douglas (2014), as ideias sobre separar, purificar, demarcar e punir transgressões têm como sua função principal impor sistematização numa experiência inerentemente desordenada. Em relação à existência de dois lados, observa-se uma clara tentativa de distinguir os públicos frequentadores desse mesmo espaço, já que se percebeu um modus operandi diferenciado e também de investimento. O ciclo de desinvestimento é retomado, ao passo que se finda uma gestão municipal.

A demolição do então Mercado do Peixe cinco anos após a conclusão das obras de reestruturação foi parte das intervenções de Requalificação da Orla do Rio Vermelho. (OBRAS..., 2015) Para além disso, tais obras fazem parte de um projeto maior que abarca diferentes pontos estratégicos na capital baiana a fim de "revitalizá-los", marcando a não exclusividade do Mercado do Peixe em relação a tal processo, mas de toda a cidade, inclusive em bairros periféricos.

O projeto implementado pela gestão municipal sofreu diversas críticas por parte dos antigos frequentadores, comerciantes e da população em geral, já que não houve um prévio debate com a população em relação ao destino das obras e dos sujeitos envolvidos com o espaço, marcando um aspecto violento e não dialógico do processo de gentrificação, diversas vezes ocultado pela mídia.

Santos (2012) identificou que, na anterior reestruturação do Mercado do Peixe, houve a demolição da estrutura antiga e a construção de um novo prédio com algumas características do antigo, como a 
distribuição dos boxes em dois lados, mas com novos detalhes também. No caso da reforma atual, a estrutura física do Mercado não foi reaproveitada e, no local, foi construído um ambiente com características totalmente novas ao que era antes, inclusive criando um novo nome e marca ao espaço, atualmente chamado de Vila Caramuru. Essa foi uma clara tentativa de não apenas criar uma nova urbanística e estética ao ambiente, mas de um movimento de construção de uma nova identidade.

$\mathrm{Na}$ época da inauguração da Vila Caramuru, o então secretário municipal de Cultura e Turismo de Salvador, Érico Mendonça, disse que o "espaço foi valorizado". (PACHECO, 2016) Entretanto, comerciantes antigos, como no caso da operadora Juliana Almeida, que comandava o Auge da Baiana, casa especializada em comida caseira, no entanto, preferia manter a tradição, dizendo: "Minha mãe começou como garçonete há 22 anos e, depois, conseguiu o próprio negócio. Oferecemos feijoada, mocotó, rabada, moqueca de peixe e maniçoba. Tudo o que era muito procurado antes". (SANTOS, 2016)

Por outro lado, há espaço para opiniões divergentes com a possibilidade de abertura de um espaço encarado como mais "diverso":

A diversidade dos produtos oferecidos na Vila Caramuru foi apontada pelos operadores de alguns dos quiosques como um diferencial que deve atrair o público. Eles acreditam que, com um cardápio mais variado, a procura deve aumentar. 'Salvador ganhou muito com uma área gourmet, com restaurantes para todos os gostos. Aqui as pessoas podem encontrar casas especializadas em caranguejo, lambreta, moqueca, feijoada, rabada e outras comidas nordestinas, além de comida italiana, carnes, sanduíches e picolés', contou o operador do Caranguejo do Pipa, Fábio Lacerda. (SANTOS, 2016)

Segundo Henández e Arnáiz (2005), nos contextos urbanos, parece que o comensal contemporâneo se converteu em um indivíduo muito mais autônomo em suas escolhas. Soma-se a isso o desejo de ampliação do espaço de tomada de decisão alimentar. Não se trata, portanto, de homogeneizar o comensal contemporâneo, mas sim de contextualizá-lo em um ambiente de moldagem social. 
Para Hall (2002), ao discutir a homogeneização cultural e global, há uma fascinação pela diferença e com a mercantilização da etnia e da alteridade. E como impacto do global, há um novo interesse sobre o local. Dessa maneira, cabe que, ao invés de pensar o global como substituto do local, seria mais prudente pensar em uma articulação entre ambos.

É na Vila Caramuru que a gourmetização, aspecto importante do processo de gentrificação em contextos comensais, aparece. O leque de opções de refeições populares não dá mais conta dos desejos da nova clientela, então ao cardápio são adicionados desde "revisitações" de pratos da culinária baiana até sorvetes e pratos da culinária italiana.

Assim, ainda que pese no discurso midiático a suposta demanda por "diversidade", o antigo Mercado do Peixe e hoje Vila Caramuru é o espaço onde o global e o regional, o tradicional e o moderno, a cidade colonial-barroca e a moderno-capitalista se estreitam e se inter-relacionam, ao passo que esses movimentos estão forjados na lógica da disputa, no embate cotidiano e no ciclo de investimento-desinvestimento pautado pelo capital.

\section{CONSIDERAÇÕES FINAIS}

Diante do conteúdo abordado, pode-se concluir que o processo de gentrificação e higienização de espaços comensais, tal qual o Mercado do Peixe, revelam-se estreitamente ligados ao discurso que é produzido pelo poder público, mídia e também pelo senso comum. Foi possível perceber o uso de adjetivos polidos e educados e termos otimistas como "revitalização", "reestruturação" e "requalificação", dentre outros eufemismos em referência ao processo de gentrificação. Isso dilui seu caráter homogeneizador, fragmentado, hierarquizado e muitas vezes violento, evitando educadamente a constituição de classe dos processos envolvidos. É possível ainda que, a própria população em geral também assuma tais discursos, ainda que sempre caibam discursos divergentes.

Tais iniciativas, portanto, tornam-se questionáveis, à medida que são descartadas as vias dialógicas e consensuais, pois são realizadas 
verticalmente pelo poder público, sem levar em os sujeitos que ali frequentavam, os aspectos particulares de suas práticas alimentares, além da dinâmica e estética espaciais.

No caso, o Mercado do Peixe foi totalmente modificado em sua estrutura física, que em nada - ou pouco - lembra o antigo espaço no que tange a esse aspecto, e passa a adotar - ao menos pelos veículos de comunicação - outro nome, em uma tentativa de promovê-lo como novo espaço. Soma-se a tal contexto a utilização de estratégias que afastam o público anterior, como: modificação do horário de funcionamento, uso de segurança particular e de hostess (recepcionistas), elevação dos preços das refeições e "gourmetização" das mesmas.

De maneira geral, constata-se que o fenômeno da gentrificação corrobora com o modelo caótico e predatório de cidade e que, consequentemente, o processo de urbanização em espaços comensais, marcado pelo esteticismo espetacular e pela dinâmica do capital, marca um aprofundamento de desigualdades sociais, econômicas e culturais em tais contextos.

\section{REFERÊNCIAS}

AMADO, J. Bahia de todos os santos: guia de ruas e mistérios. Rio de Janeiro: Record, 1991.

ARAUJO, J. M. O. Bahia: negra, mas limpinha. 2006. Dissertação (Mestrado em Ciências Sociais) - Faculdade de Filosofia e Ciências Humanas, Universidade Federal da Bahia, Salvador, 2006.

BRÁS, J. G. V. A higiene e o governo das almas: o despertar de uma nova relação. Revista Lusófona de Educação, Lisboa, v. 12, p. 113-138, 2008.

BRITO, J. Reforma de Mercado custou R\$ 3 milhões. Correio, Salvador, Caderno Mais, p. 12, 8 set. 2010.

CALABRESE, F. Estudos de requalificação e valorização urbana e paisagística do Rio Vermelho em Salvador. 2013. Dissertação (Mestrado Profissional em Conservação e Restauração de Monumentos e Núcleos Históricos) Faculdade de Arquitetura, Universidade Federal da Bahia, Salvador, 2013. 
CERTEAU, M. A invenção do cotidiano: morar, cozinhar. Petrópolis: Vozes, 1994.

DAMATTA, R. A casa e a rua: espaço, cidadania, mulher e morte no Brasil. Rio de Janeiro: Guanabara, 1987.

DAMATTA, R. Carnavais, malandros e heróis: para uma sociologia do dilema brasileiro. Rio de Janeiro: Rocco, 1997.

DAVIDSON, M.; LEES, L. New-build "gentrification" and London's riverside renaissance. Environment and Planning A: Economy and Space, Thousand Oaks, v. 37, n. 7, Jul. 2005.

DOUGLAS, M. Pureza e perigo. São Paulo: Perspectiva, 2014.

FERREIRA FILHO, A. H. Desafricanizar as ruas: elites letradas, mulheres pobres e cultura popular em Salvador (1890-1937). Afro-Ásia, Salvador, n. 21-22. p. 238-256, 1998.

GLASS, R. Introduction: Aspects of change. In: CENTRE FOR URBAN STUDIES (ed.). London: aspects of change. London: MacKibbon and Kee, 1964.

HALL, S. Who needs identity? In: HALL, S.; GAY, P. Questions of cultural identity. London: New York: Sage, 2002.

HARVEY, D. The limits to capital. Chicago: University of Chicago Press, 1982 .

HARVEY, D. The New Imperialism. Oxford: Oxford University Press, 2003. HARVEY, D. Social justice and the city. London: Edward Arnold, 1973.

HERNÁNDEZ, J. C.; ARNÁIZ, M. G. Alimentación y cultura: perspectivas antropológicas. Barcelona: Ariel, 2005.

JACQUES, P. B. Elogio aos errantes. Salvador: EDUFBA, 2012.

LARGO da Mariquita, no Rio Vermelho, em pleno abandono. A Tarde, Salvador, p. 6, 6 março 1976.

LEES, L.; SLATER, T.; WYLY, E. Gentrification. New York: Routledge, 2008.

MENDONÇA, J. Fase de decadência atinge Mercado do Rio Vermelho. $A$ Tarde, Salvador, ano 87, 9 ago. 2000. p. 4. Caderno 1.

MIGUEZ, P. C.; LOIOLA, E. A economia do carnaval da Bahia. Bahia Análise \& Dados, Salvador, v. 21, n. 2, p. 285-299, abr./jun. 2011. 
MOURA, M. Mercado do Peixe tem sábado animado. A Tarde, Salvador, p. A10, 19 set. 2010.

OBRAS de requalificação do Rio Vermelho serão realizadas em três etapas. Correio, Salvador, 22 abr. 2015. Disponível em: http://www.correio24horas. com.br/noticia/nid/obras-de-requalificacao-do-rio-vermelho-seraorealizadas-em-tres-etapas/. Acesso em: nov. 2017.

PACHECO, C. Novo Mercado do Peixe reabre essa semana com 11 novos restaurantes. Correio, Salvador, 20 mar. 2016. Disponível em: https://www. correio24horas.com.br/noticia/nid/novo-mercado-do-peixe-reabre-essasemana-com-11-novos-restaurantes/. Acesso em: nov. 2017.

PEREZ, F. É preciso cuidar também. Correio, Salvador, p. 22-23, 10 maio 2012.

PINHO, O. A. Etnografias do Brau: corpo, masculinidade e raça na reafricanização em Salvador. Estudos Feministas, Florianópolis, v. 13, n. 1, p. 127-145, jan./abr. 2005.

QUIRINO, M. A Bahia de outrora. Salvador: Livraria Progresso, 1946.

RISÉRIO, A. Uma história da cidade da Bahia. Rio de Janeiro: Versal, 2004.

SANTOS, G. Mercado do Peixe. A Tarde, Salvador, 22 jan. 2003.

SANTOS, G. Quiosques da Praça Caramurú lotam na volta do tradicional espaço. Correio, Salvador, 2 abr. 2016. Disponível em: https://www. correio24horas.com.br/noticia/nid/quiosques-da-praca-caramuru-lotamna-volta-do-tradicional-espaco/. Acesso em: nov. 2017.

SANTOS, L. A. S. O corpo, o comer e a comida: um estudo sobre as práticas corporais e alimentares no mundo contemporâneo. Salvador: Edufba, 2008.

SANTOS, L. L. O comer no mercado: a comensalidade baiana no contexto da "revitalização" do Mercado do Peixe, Salvador, Bahia. 2012. Dissertação (Mestrado em Alimentos, Nutrição e Saúde) - Escola de Nutrição, Universidade Federal da Bahia, Salvador, 2012.

SILVA, C. L. A cidade do Salvador nos seus 454 anos. Salvador: EGBA, 2006.

SMITH, N. Gentrification and uneven development. Economic Geography, Abingdon, v. 58, n. 2, p. 139-155, Apr. 1982.

SMITH, N. Uneven development: nature, capital, and the production of space. Oxford: Blackwell, 1984. 
TUDO termina nas mesas do Mercado. A Tarde, Salvador, p. 4, 20 mar. 1994.

VAN WEESEP, J. Gentrification as a research frontier. Progress in Human Geography, Thousand Oaks, v. 18, n. 1, p. 74-83, 1994. 